\title{
HELMINTOS DE PEQUENOS FELINOS SELVAGENS NO PARQUE NACIONAL DO IGUAÇU, BRASIL
}

\section{HELMINTHS OF WILD CATS IN IGUASSU NATIONAL PARK, FOZ DO IGUAÇU, BRAZIL}

\author{
M. F. D. MORAES ${ }^{1}$, M. X. SILVA², A. C. A. ALBUQUERQUE ${ }^{1}$, A. C. $\operatorname{SILVA}^{1}$, J. H. TEBALDI ${ }^{1}$, \\ E. G. LUX-HOPPE ${ }^{*}$
}

\section{RESUMO}

O Brasil é o país com maior diversidade de felinos selvagens do mundo, possuindo nove espécies descritas, entretanto pouco se conhece principalmente sobre os pequenos felinos. Atualmente todas as espécies de felinos neotropicais estão vulneráveis ou ameaçadas de extinção, e por isso surge a necessidade de se ampliar o conhecimento sobre a biologia e ecologia destas populações. Neste estudo, são descritos parasitas de uma fêmea de gato-maracajá (Leopardus wiedii), uma fêmea de gato-do-mato-pequeno (Leopardus guttulus) e um macho de jaguatirica (Leopardus pardalis) provenientes do ParNa Iguaçu, uma área prioritária para a conservação destas espécies in situ. Foi realizada a necrópsia parasitológica dos indivíduos, procedentes de atropelamento no Parna Iguaçu. Os órgãos foram seccionados, lavados e tamisados em busca de parasitas. Os helmintos recuperados foram armazenados em solução de Railliet \& Henry, processados segundo técnicas de rotina e identificados morfologicamente em acordo com chaves taxonômicas. Como resultados obteve-se para L. wiedii os helmintos Molineus felineus e Taenia sp. no intestino delgado (ID) e Pearsonema pearsoni parasitando o rim. Para L. guttulus, formas imaturas de Ascarididae no estômago e fígado, Molineus felineus, Taenia sp. e Strongyloides stercoralis no ID. Para L. pardalis obteve-se Physaloptera praeputialis no estômago, Cestódeo não identificado, Toxocara canis, Ancylostoma caninum e formas imaturas de um nematódeo Trichuroideano intestino delgado, além de formas imaturas de Acanthocephala no intestino grosso. Esta pesquisa relatou a diversidade parasitária encontrada em pequenos felinos do Parna Iguaçu e contribuiu como novos relatos para a parasitologia de carnívoros neotropicais, sendo a primeira a descrever a presença de parasitismo por $P$. pearsoni em L.wiedii e por S. stercoralis em L. guttulus, além de demonstrar a importância do estudo de helmintos em animais selvagens, pois estes ainda são escassos na região neotropical.

PALAVRAS-CHAVE: Leopardus wiedii. Leopardus guttulus. Leopardus pardalis. Parasitas.

\section{AGRADECIMENTOS: FAPESP}

ÁREA TEMÁTICA: Doenças Parasitárias

\footnotetext{
${ }^{1}$ Faculdade de Ciências Agrárias e Veterinárias da Universidade Estadual Paulista (UNESP) - Câmpus de Jaboticabal

* e.hoppe@gmail.com

${ }^{2}$ Projeto Carnívoros do Iguaçu - Parque Nacional do Iguaçu - Foz do Iguaçu - PR
} 